\title{
Parous mammary glands exhibit distinct alterations in gene expression and proliferation responsiveness to carcinogenic stimuli in Lewis rats
}

\author{
NORIHISA UEHARA ${ }^{1}$, AKIRA UNAMI ${ }^{2}$, YASUHIKO KIYOZUKA ${ }^{1}$, \\ NOBUAKI SHIKATA $^{1}$, YUJI OISHI ${ }^{2}$ and AIRO TSUBURA ${ }^{1}$ \\ ${ }^{1}$ Department of Pathology II, Kansai Medical University, Moriguchi, Osaka 570-8506; \\ ${ }^{2}$ Toxicology Research Laboratories, Fujisawa Pharmaceutical Co., Ltd., Yodogawa-ku, Osaka 532-8514, Japan
}

Received October 3, 2005; Accepted December 7, 2005

\begin{abstract}
Early full-term pregnancy affords lifetime protection against the development of breast cancer. Parityinduced protection can be reproduced in a carcinogeninduced rat mammary carcinoma model, but the molecular mechanisms of this protection against carcinogenic stimuli in rat mammary glands have not been fully characterized. To gain a better understanding of these molecular mechanisms, we used an oligonucleotide microarray to examine gene expression in parous and age-matched virgin (AMV) mammary glands of Lewis rats before and after carcinogen ( $N$-methyl- $N$-nitrosourea; $\mathrm{MNU}$ ) treatment. Parous mammary glands before MNU treatment showed up-regulation of multiple differentiation-related genes, such as whey acidic protein (Wap), casein beta (Csn2), casein gamma (Csng), lipopolysaccharide binding protein ( $\mathrm{Lbp})$, secreted phosphoprotein 1 (Spp1) and glycosylation-dependent cell adhesion molecule 1 (Glycam1). Also, parous mammary glands before MNU treatment exhibited down-regulation of growth-related genes such as regenerating islet-derived 3 alpha (Reg3a), mesothelin (Msln), insulin-like growth factor 2 (Igf2) and insulin-like growth factor binding protein 4 (Igfbp4). After MNU treatment, AMV mammary glands exhibited up-regulation of growth-related genes, such as Msln, cell division cycle 2 homolog A (Cdc2a), Igf2, Igfbp4, stathmin 1 (Stmn1) and homeobox, msh-like 1 (Msx1), whereas expression of these genes remained low in parous mammary glands. AMV mammary glands also exhibited marked up-regulation of $\mathrm{Cdc} 2 \mathrm{a}$ and $\mathrm{Stmn} 1$ in response to MNU. After MNU treatment, the PCNA labeling index
\end{abstract}

Correspondence to: Dr Norihisa Uehara, Department of Pathology II, Kansai Medical University, 10-15 Fumizono-cho, Moriguchi-shi, Osaka 570-8506, Japan

E-mail: ueharan@takii.kmu.ac.jp

Key words: mammary gland, microarray, $N$-methyl- $N$-nitrosourea, pregnancy, rat increased significantly in AMV mammary epithelial cells $(13.7 \pm 1.1 \%)$, but remained low in parous mammary glands $(3.6 \pm 0.4 \%)$. The response of AMV mammary glands to carcinogenic stimuli includes up-regulation of growth-related genes and increased cell proliferation. The lack of a similar response in parous mammary glands may explain parityinduced protection against mammary tumor development.

\section{Introduction}

Reproductive history is the most consistent risk factor affecting breast cancer incidence, regardless of geographic region and ethnicity (1). There is evidence that age at menarche, menopause and first full-term pregnancy has a significant impact on individual susceptibility to breast cancer. In particular, a number of epidemiological studies have shown that early full-term pregnancy results in a significant reduction of lifetime risk of breast cancer compared with nulliparous women $(2,3)$. Parity-induced protection against mammary cancer has also been observed in rodents. Rats $(4,5)$ and mice (6) that have undergone a full-term pregnancy are more refractory to chemically induced mammary carcinogenesis than age-matched virgins (AMVs). Pregnancy is the best-known means of physiological protection against breast cancer, and can be mimicked by short-term treatment with estrogen and progesterone $(\mathrm{E}+\mathrm{P})(7,8)$ or with human chorionic gonadotrophin (hCG) $(9,10)$. Parity- or hormone-induced protection has been demonstrated using several types of chemical carcinogens [including 7, 12dimethylbenz $(\alpha)$ anthracene (DMBA) and $N$-methyl- $N$ nitrosourea $(\mathrm{MNU})]$ and several strains of mice $(\mathrm{C} 3 \mathrm{H} / \mathrm{Sm}$ and BD2/fF1) and rats (Sprague-Dawley, Wistar-Furth and Lewis) (4-6,11).

Several hypotheses have been proposed to explain the mechanism(s) of parity-induced protection against rat mammary carcinogenesis, based on phenotypic features of parous and hormone-treated mammary glands. The bestknown hypothesis is that protection is the result of differentiation of mammary gland target structures (terminal end buds; TEBs), which are considered to be the site of origin of mammary carcinoma (12). In addition, changes in the phenotypes of parous mammary epithelial cells are 
thought to be important, e.g. decreased proliferation activity, increased capacity for DNA repair, and decreased carcinogen binding to DNA of epithelial cells $(13,14)$. Another hypothesis is that protection is the result of an altered systemic hormonal milieu with reduced circulating levels of prolactin (PRL) and growth hormone $(\mathrm{GH})$, which regulate mammary gland development (4). Parous mammary glands have also exhibited decreased expression of estrogen receptor $\alpha$ and epidermal growth factor receptor (4). Thus, persistent changes in mammary gland structures, mammary epithelial cell phenotype or hormonal environment may be involved in parity-induced protection against carcinogenesis in rats. Studies have shown persistent changes in gene expression in parous rodents, compared to AMVs $(15,16)$. However, the cellular and molecular mechanisms that underlie parity-induced protection remain largely unknown. Therefore, there is a need to elucidate the molecular mechanisms responsible for parityinduced protection against mammary carcinoma in rats.

In the present study, we performed oligonucleotide microarray analyses to identify candidate genes for parityinduced protection against mammary carcinoma in rats, and used real-time PCR analyses to quantify differences in expression of these genes between parous and AMV mammary glands of inbred Lewis rats before and after MNU treatment. In addition, we compared levels of cell proliferation before and after MNU treatment between parous and AMV mammary glands.

\section{Materials and methods}

Animals. Twelve-week-old pregnant and AMV inbred Lewis rats were purchased from Charles River Japan (Hino). The animals were maintained under standard laboratory conditions $\left(22^{\circ} \mathrm{C}, 60 \pm 10 \%\right.$ humidity, $12 \mathrm{~h}$ dark/light cycle), and fed a commercial pellet diet (CMF; Oriental Yeast, Kyoto, Japan)

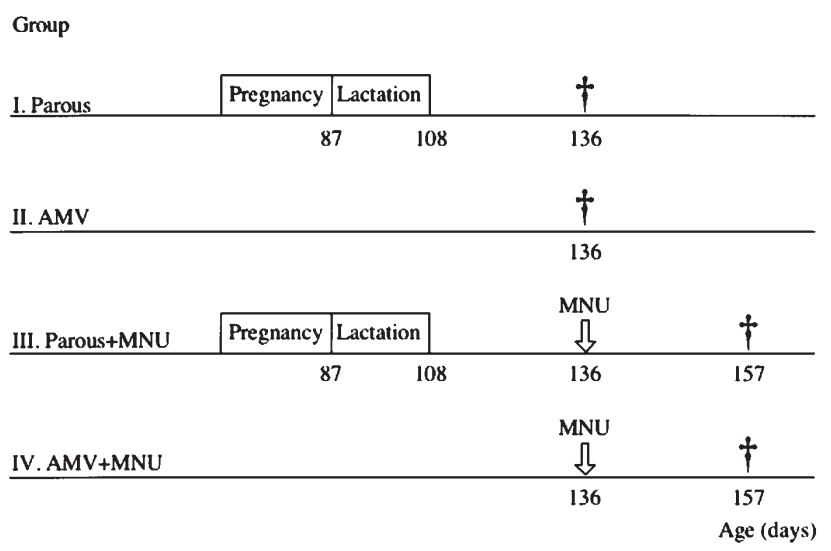

Figure 1. Schematic representation of the experimental protocol. $\uparrow$, Time at which rats were sacrificed. MNU, $50 \mathrm{mg} / \mathrm{kg}$ body weight MNU was injected into parous and AMV animals (groups III and IV, respectively) at 136 days of age.

and water ad libitum throughout the experiment. The Animal Experimentation Committee at Kansai Medical University approved all procedures involving animals. Pregnant and AMV rats (10 animals each) were used for the experiments. After parturition (at 87 days of age), parous animals were allowed to nurse their offspring for 21 days. At 108 days of age, the litters were removed, and the parous animals underwent 28 days of postlactational involution. At 136 days of age, parous and AMV rats (5 animals each) were sacrificed, and the remaining animals (5 parous and 5 AMV rats) received a single intraperitoneal $50 \mathrm{mg} / \mathrm{kg}$ dose of $\mathrm{N}$-methyl- $\mathrm{N}$ nitrosourea (MNU; Nacalai Tesque, Kyoto, Japan). Three weeks after MNU administration, both parous and AMV rats (age, 157 days) were sacrificed. A schematic representation of the experimental protocol is shown in Fig. 1.

Table I. List of primers used for real-time PCR analysis.

\begin{tabular}{|c|c|c|}
\hline Gene name (gene symbol) & Forward primer & Reverse primer \\
\hline Whey acidic protein (Wap) & GCCCAGAATGACATGTGTTG & TTGTTGCAGCATTTCATGGT \\
\hline Casein beta (Csn2) & TGGGCСTATCATTTCTCCTG & GTCTGAGGAAAAGCCTGCAC \\
\hline Casein gamma (Csng) & AGGGCAATGGTGTGTTCTTC & GGGCCATTGGTTCACACTAC \\
\hline Lipopolysaccharide binding protein (Lbp) & АATCCAAAGTCGGCATGTTC & AGTCGAGGTCGTGGAGCTTA \\
\hline \multicolumn{3}{|l|}{ Glycosylation-dependent } \\
\hline cell adhesion molecule 1 (Glycam1) & GCAGGAAGAGACCACCTCAG & CCAAGAGGTGGTGGTCAGAT \\
\hline Secreted phosphoprotein 1 (Spp1) & GAGGAGAAGGCGCATTACAG & ATGGCTTTCATTGGAGTTGC \\
\hline Amphiregulin (Areg) & TGGCAGTGAACTCTCCACAG & ССтTTGСстСсСтTTTTСтT \\
\hline Regenerating islet-derived 3 alpha (Reg3a) & TCTGAAGTGGGGAGACCATC & CGGATGAAGGAAGATGGAAA \\
\hline Mesothelin (Ms1n) & ACCTGGACAGTCTGGGTTTG & CAGGAGCCTTAGGAGTGGTG \\
\hline Cell division cycle 2 homolog A (Cdc2a) & GGGTCCGTTGTAACCTGTTG & TССTTСTTССTCGСTTTCAА \\
\hline Insulin-like growth factor 2 (Igf2) & GTCCTGCTCCCAАССАТTTA & CAGAAGTCAGGCCAGGTAGC \\
\hline Insulin-like growth factor binding protein 4 (Igfbp4) & ATGGCCAAAGTGAGAGATCG & GACACTGTTTGGGGTGGAAG \\
\hline Stathmin 1 (Stmnl) & AGCAAAATGGCAGAGGAGAA & TTAGTCAGCCTCGGTCTCGT \\
\hline Homeobox, msb-like 1 (Msxl) & CTACGCAAGCACAAGACCAA & TTCACCTGGGTCTCGGTAAG \\
\hline Actin, beta (Actb) & AGCCATGTACGTAGCCATCC & СTCTCAGCTGTGGTGGTGAA \\
\hline Cytokeratin 8 (Ck8) & CCAAGCTGGAGGATCTGAAG & TTCGTGTGGATGCTCATGTT \\
\hline
\end{tabular}




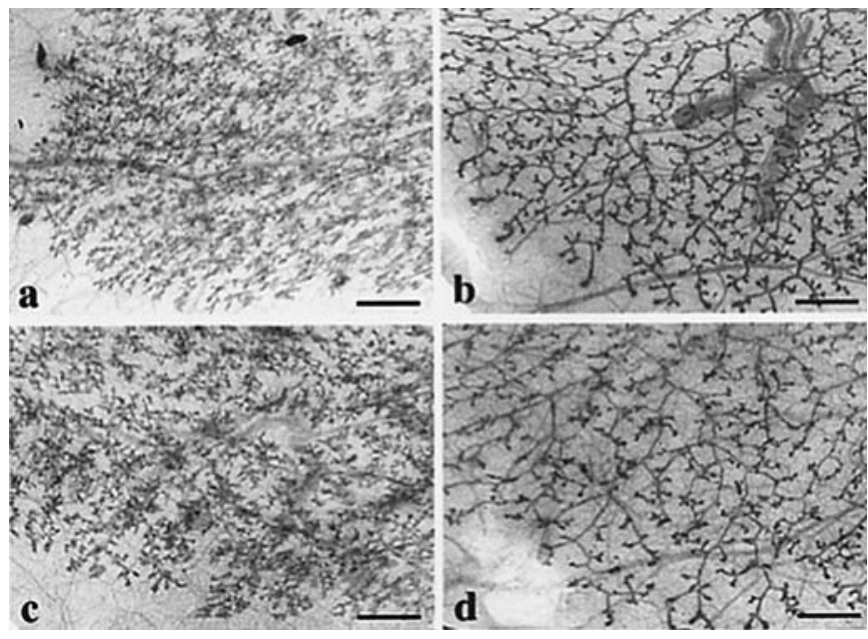

Figure 2. Whole mounts of mammary glands obtained from parous (a), AMV (b), parous plus MNU (c) and AMV plus MNU (d). Note the increased ductal branching and alveolar formation in parous mammary glands before (a, 136 days of age) and after (c, 157 days of age) MNU treatment, compared with corresponding AMV mammary glands (b and d, respectively). Scale bar, $1.0 \mathrm{~mm}$.

Tissue collection and RNA isolation. For microarray and real-time PCR analyses, 4th inguinal mammary glands were collected from 5 animals per group (group I, parous; group II, AMV; group III, parous+MNU; and group IV, $\mathrm{AMV}+\mathrm{MNU}$ ). Mammary tissues were snap-frozen in liquid nitrogen immediately after removal and stored at $-80^{\circ} \mathrm{C}$ until use. Total RNA was isolated using QIAzol reagent (Qiagen, Valencia, CA) according to the manufacturer's instructions. Frozen tissues were ground to a powder in liquid nitrogen using a mortar and pestle before being added to QIAzol reagent for homogenization. RNA was further purified using the RNeasy Mini kit (Qiagen).

Microarray analysis. For microarray analyses, equal amounts of purified RNA from 5 animals per group were combined into RNA pools. The quality of each RNA pool was determined using an Agilent 2100 Bioanalyzer (Agilent Technologies, Palo Alto, CA). An oligonucleotide array, containing approximately 20,000 sequences corresponding to known genes, expression sequence tags (ESTs) and unknown genes, was used to compare the gene expression patterns of parous and AMV mammary glands before and after MNU treatment. Rat oligo microarray kits (G4130A) were purchased from Agilent Technologies. Labeled cRNA was synthesized from $1.0 \mu \mathrm{g}$ of total RNA using a Low RNA Input Fluorescent Linear Amplification kit (Agilent Technologies) according to the manufacturer's instructions. The first-strand cDNA was generated by in vitro transcription using the Moloney murine leukemia virus (MMLV) reverse transcriptase and oligo dTT7 promoter primer. cRNA was then generated using T7 RNA polymerase, and labeled with cyanine 3 (Cy3)-CTP (Perking-Elmer/NEN Life Sciences, Boston, MA). For the purification of labeled cRNA samples, unincorporated dyelabeled nucleotides were removed using an RNeasy Mini kit (Qiagen). The quality of each labeled cRNA was determined using an Agilent 2100 Bioanalyzer (Agilent Technologies). Each array was hybridized in hybridization buffer containing fragmented Cy3-labeled cRNA for $17 \mathrm{~h}$ at $60^{\circ} \mathrm{C}$ with constant

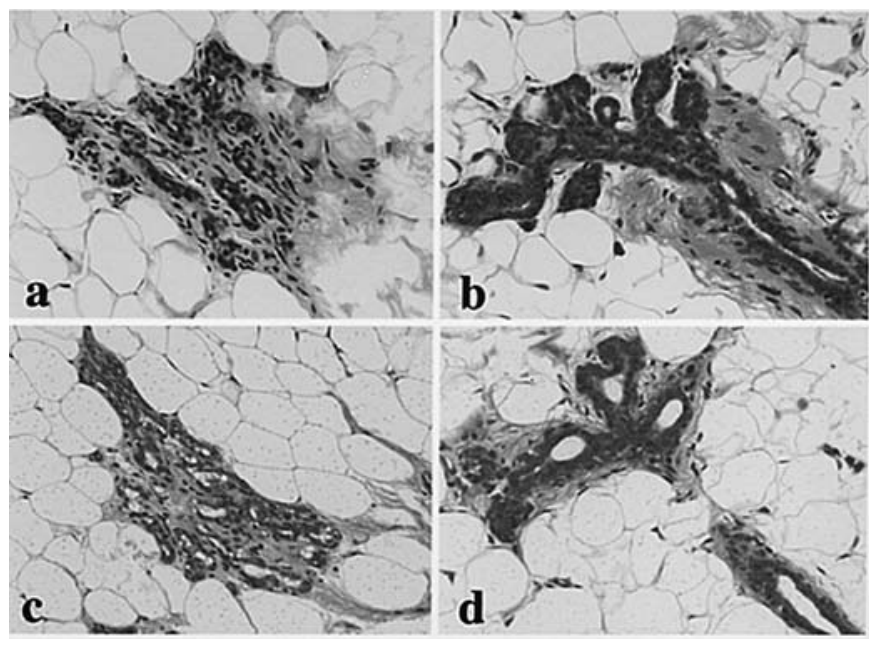

Figure 3. Photomicrographs of mammary glands. Untreated parous mammary glands (a), untreated AMV mammary glands (b), MNU-treated parous mammary glands (c), and MNU-treated AMV mammary glands (d). Atrophic cells without secretory activity were observed in untreated parous mammary glands and MNU-treated parous mammary glands (a and c, respectively). Original magnification, x200.

rotation (5 rpm). After hybridization, the slides were washed and scanned using an Agilent Microarray Scanner (Agilent Technologies). Fluorescence intensities on scanned images were quantified, and the values were corrected for the background level and normalized using Agilent Feature Extraction software (Agilent Technologies). The complete dataset of the microarray used in this study has been deposited in the database of the National Center for Biotechnology Information's Gene Expression Omnibus (GEO; http:// www.ncbi.nlm.nih.gov/geo/; accession no. GSE2726 [NCBI GEO]).

Quantitative analysis of gene expression. Gene expression was analyzed by performing quantitative real-time PCR using iCycler iQ Optical System Software version 3.0A (BioRad, Hercules, CA). The cDNA was reverse-transcribed from $1.0 \mu \mathrm{g}$ of RNA from each of 5 animals per group, using a first-strand cDNA Synthesis kit (Invitrogen, Grand Island, NY). Primers for the quantitative real-time PCR analysis were designed using Primer3 software available at http://www.primer3.com for genes differentially expressed in microarray analyses (Table I). The PCR for each primer set was performed in triplicate using iQ SYBR Green Supermix (Bio-Rad). The expression of each target cDNA, relative to rat $B$-actin, was calculated using the comparative threshold cycle (CT) method and the Q-gene software (17). In addition, cytokeratin 8 (Ck8) expression was compared among groups to compensate for differences in the number of epithelial cells in the samples.

Histology, immunohistochemistry and whole-mount analyses. For histological and immunohistochemical analyses, the left 2nd and 3rd thoracic mammary glands were removed, fixed in $10 \%$ neutral-buffered formalin, sectioned, then either stained with hematoxylin and eosin or used for immunohistochemistry. For whole mounts, the right 2 nd and $3 \mathrm{rd}$ thoracic mammary glands were dehydrated in graded alcohol, defatted in methyl salicylate, stained with hematoxylin and 
Table II. Differences in gene expression between parous and AMV mammary glands.

\begin{tabular}{|c|c|c|c|c|}
\hline Genes & $\begin{array}{c}\text { Gene } \\
\text { symbol }\end{array}$ & Function & $\begin{array}{l}\text { Fold } \\
\text { change }\end{array}$ & $\begin{array}{l}\text { GenBank } \\
\text { accession no. }\end{array}$ \\
\hline \multicolumn{5}{|l|}{ Up-regulated } \\
\hline Whey acidic protein & Wap & Milk protein & 5.3 & NM_053751 \\
\hline Casein beta & $\operatorname{Csn} 2$ & Milk protein & 7.7 & NM_017120 \\
\hline Casein gamma & Csng & Milk protein & 16.3 & XM_341197 \\
\hline Lipopolysaccharide binding protein & Lbp & Antibacterial/milk protein & 2.2 & NM_017208 \\
\hline Ig germline alpha $H$-chain $C$-region gene & & Immune response & 5.3 & M13801 \\
\hline Secreted phosphoprotein 1 & Spp1 & Immune response & 2.4 & NM_012881 \\
\hline Matrix metalloproteinase 12 & $\mathrm{Mmpl2}$ & Macrophage elastase activity & 2.6 & NM_053963 \\
\hline Granzyme A & Gzma & Granzyme A activity & 2.3 & NM_153468 \\
\hline Glycosylation-dependent cell adhesion molecule 1 & Glycam1 & Cell adhesion & 5.3 & NM_012794 \\
\hline Glycoproiein (transmembrane) nmb & Gpnmb & Cell adhesion & 2.4 & NM_133298 \\
\hline Neuropilin 2 & Nrp2 & Cell adhesion & 2.1 & NM_030869 \\
\hline Aquaporin 2 & Aqp2 & Plasma membrane & 2.5 & NM_012909 \\
\hline Leukotriene C4 synthase & Ltc4s & Membrane fraction & 2.0 & NM_053639 \\
\hline Complement component/actor $h$ & Cfh & Lipid transporter activity & 2.0 & NM_130409 \\
\hline Carbonic anhydrase 2 & $\mathrm{Ca} 2$ & Hydratase & 2.3 & NM_019291 \\
\hline \multicolumn{5}{|l|}{ Down-regulated } \\
\hline Amphiregulin & Areg & Cell proliferation & 2.2 & NM_017123 \\
\hline Regenerating islet-derived 3 alpha & $\operatorname{Reg} 3 \mathrm{a}$ & Cell proliferation & 2.9 & NM_172077 \\
\hline Mesothelin & Ms1n & Cell adhesion & 2.2 & NM_031658 \\
\hline Latent transforming growth factor beta binding protein 2 & Ltbp2 & Cell adhesion & 2.0 & NM_021586 \\
\hline Fibronectin 1 & Fnl & Cell adhesion & 2.2 & NM_019143 \\
\hline Myosin, light polypeptide 2 & Myl2 & Cytoskeleton & 2.1 & NM_012605 \\
\hline Peptidyl arginine deiminase, type II & Pdi2 & Protein modification & 2.3 & NM_017226 \\
\hline
\end{tabular}

mounted in balsam. The proliferative status of mammary epithelial cells in parous and AMV rats before and after MNU treatment was quantified using the proliferating cell nuclear antigen (PCNA) labeling index. PCNA immunohistochemistry was performed using the labeled streptavidin-biotin (LSAB) method with an antibody against PCNA (PC10; Novocastra, Newcastle upon Tyne, UK), using an LSAB Staining kit (Dako Cytomation, Carpinteria, CA) according to the manufacturer's instructions. The PCNA labeling index was determined as described previously (5).

Statistical analysis. Data were analyzed using the Student's $\mathrm{t}$-test. Differences were considered significant at a p-value $<0.05$.

\section{Results}

Morphological analyses of mammary glands. Morphological changes in parous and AMV mammary glands before and after MNU treatment were confirmed by whole-mount analyses (Fig. 2). In parous mammary glands after 28 days of postlactational involution, we observed highly branched epithelial trees with small alveoli (Fig. 2a), compared with AMVs (Fig. 2b). At 21 days after MNU treatment (after 49 days of postlactational involution), parous mammary glands continued to exhibit highly branched epithelial structures, compared with AMV mammary glands (Fig. 2c and d, respectively). After MNU treatment, parous mammary glands exhibited a degree of ductal branching that was similar to the branching observed in parous glands before MNU treatment (Fig. 2a and c). Histologically, after 28 days of postlactational involution, epithelial structures of parous mammary glands consisted mainly of non-secretory atrophic cells (Fig. 3a), and similar cell features were seen after 49 days of postlactational involution (Fig. 3c). Before and after MNU treatment (Fig. 3b and d), AMV mammary glands exhibited a lesser degree of alveolar structural development than parous mammary glands (Fig. 3a and c).

Comparison of gene expression before MNU treatment between parous and AMV mammary glands by microarray analyses. A total of 57 genes, including EST genes and unknown genes, exhibited a 2-fold difference in expression between parous and AMV mammary glands with 44 upregulated and 13 down-regulated genes in parous mammary glands, compared with AMV mammary glands (data not shown). A summary of 22 known genes is shown in Table II. Several of these genes encode mammary differentiation markers [such as whey acidic protein (Wap), casein beta (Csn2) and casein gamma (Csng)] that were up-regulated in 
Table III. Differences in gene expression between parous and AMV mammary glands after MNU treatment.

\begin{tabular}{|c|c|c|c|c|}
\hline Genes & $\begin{array}{c}\text { Gene } \\
\text { symbol }\end{array}$ & Function & $\begin{array}{c}\text { Fold } \\
\text { change }\end{array}$ & $\begin{array}{c}\text { GenBank } \\
\text { accession no }\end{array}$ \\
\hline \multicolumn{5}{|l|}{ Up-regulated } \\
\hline Casein beta & Csn 2 & Milk protein & 3.8 & NM_017120 \\
\hline Casein gamma & Csng & Milk protein & 3.3 & XM_341197 \\
\hline Lipopolysaccharide binding protein & Lbp & Antibacterial/milk protein & 2.1 & NM_017208 \\
\hline Ig germline alpha $H$-chain $C$-region gene & & Immune response & 3.6 & M13801 \\
\hline Glycosylation-dependent cell adhesion molecule 1 & Glycam1 & Cell adhesion & 3.0 & NM_012794 \\
\hline Corticotrophin releasing hormone receptor 2 & Crhr2 & Plasma membrane & 2.3 & NM_022714 \\
\hline Angiotensin 11 type-1 receptor & Agtrl & Plasma membrane & 2.4 & NM_031009 \\
\hline Putative G protein-coupled receptor snGPCR32 & $\operatorname{Edg} 7$ & Plasma membrane & 2.0 & NM_023969 \\
\hline D site albumin promoter binding protein & Dbp & DNA binding & 2.8 & NM_012543 \\
\hline \multicolumn{5}{|l|}{ Down-regulated } \\
\hline Amphiregulin & Areg & Cell proliferation & 2.0 & NM_017123 \\
\hline Regenerating islet-derived 3 alpha & $\operatorname{Reg} 3 a$ & Cell proliferation & 2.1 & NM_172077 \\
\hline Mesothelin & Ms1n & Cell adhesion & 2.2 & NM_031658 \\
\hline Cell division cycle 2 homolog $A$ & $\mathrm{Cdc} 2 \mathrm{a}$ & Cell cycle & 2.4 & NM_019296 \\
\hline Insulin-like growth factor 2 & Igf2 & Growth factor & 2.2 & NM_031511 \\
\hline Insulin-like growth factor binding protein 4 & Igfbp4 & Growth factor binding & 2.0 & XM_340897 \\
\hline Stathmin 1 & Stmnl & Cell proliferation & 2.1 & NM_017166 \\
\hline Homeobox, msb-like 1 & Msxl & Development & 2.1 & NM_031059 \\
\hline Nuclear factor, interleukin 3, regulated & Nfil3 & DNA binding & 2.1 & NM_053727 \\
\hline Vascular cell adhesion molecule 1 & Vcami & Cell adhesion & 2.4 & NM_012889 \\
\hline Peptidyl arginine deiminase, type II & Pdi2 & Protein modification & 2.4 & NM_017226 \\
\hline Stearoyl coenzyme A desaturase 2 & $\mathrm{Scd} 2$ & Fatty acid biosynthesis & 2.3 & NM_031841 \\
\hline Fatty acid elongase 2 & rELO2 & Fatty acid biosynthesis & 2.1 & NM_134383 \\
\hline \multicolumn{5}{|l|}{ Calcium channel, voltage-dependent, } \\
\hline T-type, alpha IG subunit & Cacnalg & Ion channel activity & 2.0 & NM_031601 \\
\hline
\end{tabular}

parous mammary glands. In addition, lipopolysaccharide binding protein (Lbp) (18), secreted phosphoprotein 1 (Spp1) (19) and glycosylation-dependent cell adhesion molecule 1 (Glycam1) (20), which are reportedly involved in mammary gland differentiation, were found to be up-regulated in parous mammary glands. In contrast, genes involved in cell growth, such as amphiregulin (Areg) and regenerating islet-derived 3 alpha (Reg3a), were found to be down-regulated in parous mammary glands. We also found that mesothelin (Msln), which has been shown to be involved in mammary epithelial cell proliferation (21), was down-regulated in parous mammary glands.

Comparison of gene expression after MNU treatment between parous and AMV mammary glands by microarray analyses. A total of 71 genes that included EST and unknown genes exhibited a 2-fold difference in expression with 42 up-regulated and 29 down-regulated genes in parous mammary glands, compared with AMV mammary glands (data not shown). A summary of 23 known genes is shown in Table III. Among those 23 genes, up-regulation of differentiation-related genes (Csn2, Csng, Lbp and Glycam1) and down-regulation of growth-related genes (Areg, Reg3a and Msln) were observed in parous mammary glands after MNU treatment. In addition to these alterations in gene expression, we observed downregulation of growth-related genes, such as cell division cycle control 2 homolog A (Cdc2a), insulin-like growth factor 2 (Igf2), insulin-like growth factor binding protein 4 (Igfbp4), stathmin 1 (Stmn1), homeobox, and msh-like 1 (Msx1) in parous mammary glands after MNU treatment.

Differences in gene expression in parous and AMV mammary glands in response to MNU treatment by microarray analyses. Changes in gene expression in 157-day-old parous and AMV mammary glands (obtained 21 days after MNU treatment) were compared to those of 136-day-old (MNU-untreated) parous and AMV mammary glands. In parous mammary glands, 34 genes, including EST genes and unknown genes, exhibited a 2-fold difference in expression with 21 up-regulated and 13 down-regulated genes after MNU treatment (data not shown). A summary of 5 known genes is shown in Table IV. Of those 5 genes, zinc finger protein 4 (Azf4) and angiotensin II type-1 receptor (Agtr1) were up-regulated, and claudin-7 (Cldn7), alpha-3 type IV collagen (COL4A3) and Spp1 were down-regulated. In AMV mammary glands, 55 genes, including EST and unknown genes, exhibited a 2-fold 
Table IV. Changes in gene expression in parous mammary glands in response to MNU treatment.

\begin{tabular}{|c|c|c|c|c|}
\hline Genes & $\begin{array}{c}\text { Gene } \\
\text { symbol }\end{array}$ & Function & $\begin{array}{c}\text { Fold } \\
\text { change }\end{array}$ & $\begin{array}{c}\text { GenBank } \\
\text { accession no }\end{array}$ \\
\hline \multicolumn{5}{|l|}{ Up-regulated } \\
\hline Zinc finger protein 4 & Azf4 & Transcription factor & 2.5 & U78115.1 \\
\hline Angiotensin II type 1 receptor & Agtrl & Plasma membrane & 2.6 & NM_031009 \\
\hline \multicolumn{5}{|l|}{ Down-regulated } \\
\hline Claudin-7 & Cldn7 & Cell adhesion & 2.8 & BM386659 \\
\hline Alpha-3 type IV collagen & COL4A3 & Cell adhesion & 2.5 & $\mathrm{~L} 47281.2$ \\
\hline Secreted phosphoprotein 1 (osteopontin) & Spp1 & Immune response & 2.1 & NM_012881 \\
\hline
\end{tabular}

Table V. Changes in gene expression in virgin mammary glands in response to MNU treatment.

\begin{tabular}{|c|c|c|c|c|}
\hline Genes & $\begin{array}{c}\text { Gene } \\
\text { symbol }\end{array}$ & Function & $\begin{array}{l}\text { Fold } \\
\text { change }\end{array}$ & $\begin{array}{c}\text { GenBank } \\
\text { accession no. }\end{array}$ \\
\hline \multicolumn{5}{|l|}{ Up-regulated } \\
\hline Cell division cycle 2 homolog $A$ & $\mathrm{Cdc} 2 \mathrm{a}$ & Cell cycle & 2.4 & NM_019296 \\
\hline Stathmin 1 & Stmn1 & Cell proliferation & 2.3 & NM_017166 \\
\hline High mobility group box 2 & Hmgb2 & DNA binding & 2.3 & NM_017187 \\
\hline Pyruvate carboxylase & $\mathrm{Pc}$ & Pyruvate carboxylase activity & 3.1 & NM_012744 \\
\hline Malic enzyme I, soluble & Mel & Malate dehydrogenase activity & 2.7 & NM_012600 \\
\hline Transketolase & Tkt & Transketolase activity & 2.6 & $\mathrm{BI} 282629$ \\
\hline ATP citrate lyase & Acly & ATP citrate synthase activity & 2.2 & NM_016987 \\
\hline Carbonyl reductase I & Cbr1 & NADPH activity & 2.2 & NM_019170 \\
\hline Fatty acid elongase 2 & rELO2 & Fatty acid biosynthesis & 3.7 & NM_134383 \\
\hline Fatty acid synthase & Fasn & Fatty acid metabolism & 3.2 & NM_017332 \\
\hline Thyroid hormone responsive protein & Thrsp & Lipid metabolism & 3.6 & NM_012703 \\
\hline Pyruvate dehydrogenase kinase 1 & Pdkl & Protein kinase activity & 2.0 & NM_053826 \\
\hline Diazepam binding inhibitor & Dbi & Acyl-CoA binding & 2.1 & NM_031853 \\
\hline Retinal-binding protein & Rbp & Retinoid binding & 2.5 & AA858962 \\
\hline Brain protein 44 -like & Brp441 & Unknown & 2.6 & NM_133561 \\
\hline \multicolumn{5}{|l|}{ Down-regulated } \\
\hline Connective tissue growth factor & Ctgf & Plasma membrane & 2.4 & NM_022266 \\
\hline Nectin-1 & & Cell adhesion & 2.1 & AF091111.1 \\
\hline$D$ site albumin promoter binding protein & Dbp & DNA binding & 2.1 & NM_012543 \\
\hline Neuronatin & Nnat & Development & 2.4 & NM_053601 \\
\hline Sodium channel,type 10, alpha polypeptide & Scn10a & Sodium ion transport & 2.1 & NM_017247 \\
\hline
\end{tabular}

difference in expression with 35 up-regulated and 20 downregulated genes after MNU treatment (data not shown). A summary of 20 known genes is shown in Table V. Among those 20 genes, growth-related genes such as $\mathrm{Cdc} 2 \mathrm{a}$ and Stmn1 were up-regulated. In addition, we observed the up-regulation of genes involved in energy metabolism and fatty acid metabolism, such as pyruvate carboxylase $(\mathrm{Pc})$, malic enzyme 1 (Me1), transketorase (Tkt), ATP citrate lyase (Acyl), carboxyl reductase 1 (Cbr1), fatty acid elongase 2 (rELO2), fatty acid synthase (Fasn) and thyroid hormone responsive protein (Thrsp).
Confirmation of differences in expression of differentiationand growth-related genes in parous and AMV mammary glands by real-time PCR analysis. The results of oligonucleotide microarray analyses showed the up-regulation of differentiationrelated genes and down-regulation of growth-related genes in parous mammary glands before and after MNU treatment, compared to AMV mammary glands. We next used quantitative real-time PCR analysis to further analyze the expression levels of differentiation-related genes (Wap, Csn2, Csng, Lbp, Spp1 and Glycam1) and growth-related genes (Areg, Reg3a, Msln, Cdc2a, Igf2, Igfbp4, Stmn1 and 

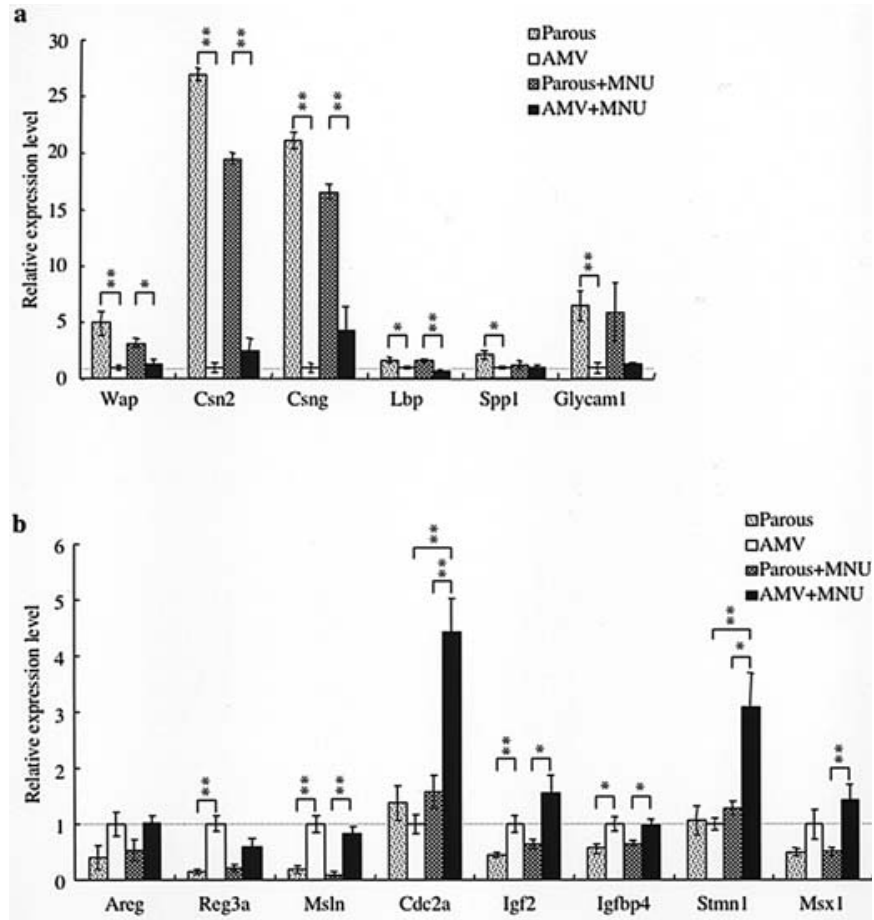

Figure 4. Analyses of gene expression in parous and AMV mammary glands before and after MNU treatment. (A) Differentiation-related and (B) growthrelated genes identified by microarray analyses were further analyzed by quantitative real-time PCR. For each target gene, the expression was normalized to $\beta$-actin, and the expression level is shown relative to the value for AMV (designated as 1) for comparison. Data represent the means $\pm \mathrm{SE}$ of triplicate PCR assays for each of 5 mammary glands per group. ${ }^{* *} \mathrm{p}<0.01$ and ${ }^{*} \mathrm{p}<0.05$.

Msx1) using each of the 5 mammary gland samples obtained from each of the 4 experimental groups. Results obtained for differentiation- and growth-related genes are shown in Fig. 4a and b, respectively. Regardless of MNU treatment, parous mammary glands exhibited persistent up-regulation of Wap, Csn2, Csng, Lbp and Glycam1. In contrast, Spp1 expression in parous mammary glands was only transiently up-regulated, and declined until it reached the same level as that of AMV mammary glands after MNU treatment (Fig. 4a). Before MNU treatment, parous mammary glands exhibited significant down-regulation of growth-related genes such as Reg3a, Msln, Igf2 and Igfbp4, compared with AMV mammary glands. After MNU treatment, AMV mammary glands showed significant up-regulation of growth-related genes such as Msln, Cdc2a, Igf2, Igfbp4, Stmn1 and Msx1 compared with parous mammary glands. In addition, we observed marked up-regulation of Cdc2a and Stmn1 in AMV mammary glands in response to MNU, whereas the expression of these genes in parous mammary glands remained at a steady level (Fig. 4b). To determine whether there were differences in the number of epithelial cells between groups, we compared levels of Ck8 expression. There were no significant differences in the Ck8 expression levels between the groups (data not shown), indicating that the changes we observed in differentiationand growth-related gene expression were not due to differences in the number of epithelial cells. before and after MNU treatment. Before MNU treatment,



Figure 5. Analysis of cell proliferation in mammary epithelial cells of AMV and parous rats before and after MNU treatment. ${ }^{* *} \mathrm{p}<0.01$ and ${ }^{*} \mathrm{p}<0.05$. Data represent the means \pm SE of 5 mammary glands per group.

PCNA-positive cells comprised $3.3 \pm 0.6 \%$ and $5.6 \pm 0.4 \%$ of cells in parous and AMV mammary glands, respectively (Fig. 5). In contrast, after MNU treatment, a significant increase in PCNA labeling was observed in AMV mammary glands $(13.7 \pm 1.1 \%)$, whereas PCNA labeling remained at a low level in parous mammary glands $(3.6 \pm 0.4 \%)$.

\section{Discussion}

The preventive effects of early full-term pregnancy against breast cancer are well documented in humans and rodent models of chemically induced mammary carcinogenesis (2-6). However, the cellular and molecular mechanisms of parity-induced protection are still largely unknown. Using oligonucleotide array analyses, we identified known genes that were differentially expressed in parous and AMV mammary glands before (22 genes) and after (23 genes) MNU treatment. Researchers have speculated that parityinduced protection against mammary cancer may be due to structural changes in the mammary glandular tree caused by pregnancy (12). In the present study, whole-mount analyses showed that parous mammary glands exhibited highly branched epithelial trees possessing alveoli, and were more differentiated than AMV mammary glands (Fig. 2). Histological analyses revealed that parous mammary glands consisted mainly of non-secretory atrophic cells (Fig. 3) (4,5). These structural changes in parous mammary glands were accompanied by the up-regulation of genes encoding mammary epithelial differentiation markers such as Wap, Csn2 and Csng, indicating that parous mammary glands consist of mammary cells that are more differentiated than those of AMV mammary glands. Moreover, we also found that differentiation-related genes such as Lbp (18), Spp1 (19) and Glycam1 (20) were up-regulated in parous mammary glands. The highly branched structure of ductal trees observed in parous mammary glands after 28 days postlactational involution was still present 21 days after MNU treatment (after 49 days of postlactational involution) (Fig. 2). Consistent with this observation, parous mammary glands exhibited persistent up-regulation of differentiation-related genes such as Wap, Csn2, Csng, Lbp and Glycam1, but not Spp1, after MNU treatment (Fig. 4a). 
Parity induces increased expression of differentiation-related genes such as Wap, Csn2, Csng, Lbp and Spp1 (also known as osteopontin or early T-cell activating protein) (16). In addition to pregnancy, short-term treatment with $\mathrm{E}+\mathrm{P}$ has protective effects against mammary cancer $(7,8)$, and it has been reported that casein genes are up-regulated in response to $\mathrm{E}+\mathrm{P}$ treatment (15). Induction of differentiation of mammary glands as a consequence of pregnancy appears to be important for protection against mammary cancer. However, induction of mammary gland differentiation by the potent differentiating agent perphenazine does not confer protection against mammary carcinogenesis (22). Structural changes in mammary glands may not be the only major factor in parity-induced protection; it is possible that up-regulation of differentiationrelated genes and alteration of their downstream pathways affects refractoriness to mammary carcinogenesis. In addition, parity-induced up-regulation of genes specifically expressed in hematopoietic cells has been reported (16). Consistent with this finding, our microarray data showed up-regulation of Lbp, Ig germline alpha $H$-chain $C$-region gene, Spp1 and matrix metalloproteinase 12 (Mmp12), which may influence the immune system in parous mammary glands.

Parous mammary glands tend to down-regulate growthrelated genes such as Areg, Reg3a and Msln, in contrast to their up-regulation of differentiation-related genes. Areg belongs to the epidermal growth factor family, and plays an important role in promoting mammary epithelial cell proliferation and development of mammary ducts $(23,24)$. In addition, Areg overexpression in primary human breast cancers has been reported (25). Consistent with the present findings, a previous study has shown persistent up-regulation of Areg in parous mammary glands of rats and mice (16). Although there have been no reports of expression of Reg3a (a member of the Reg family) in mammary glands, Reg3a has been found to be involved in regeneration and growth of pancreatic ß-cells after DNA damage (26). Msln has been shown to be elevated in Wnt-1 transgenic mice whose mammary epithelial cells exhibit transformed phenotype (20). These findings suggest that parity-induced down-regulation of these genes is important for maintenance of the refractory state against mammary carcinogenesis.

After MNU treatment, the expression of Msln, Cdc2a, Igf2, Igfbp4, Stmn1 and Msx1 was down-regulated in parous mammary glands, compared with AMV mammary glands (Fig. 4b). Overexpression of Cdc2 (27), Igf2 (28), Igfbp4 (29) and Stmn1 (30) in human breast cancer has been reported. Cyclin D1 plays a major role in mammary gland development and carcinogenesis (31), and Areg (32), Msln $(21,33)$ and Msx1 (34) are involved in cyclin D1 expression. The regulation of cyclin D1 via these genes in parous mammary glands may be a key factor in the protection against mammary carcinogenesis. Reduced circulating levels of PRL and GH in rats are thought to play pivotal roles in parity-induced protection against mammary carcinogenesis (4). It has been reported that Igf2 is a mediator of PRL-induced mammary gland development (35). Reduced circulating levels of PRL may result in suppression of Igf 2 in parous mammary glands after MNU treatment.

The most important findings of the present study were the alterations in gene expression in AMV mammary glands after MNU treatment. Parous and AMV mammary glands exhibited quite different changes in gene expression in response to carcinogen challenge. It is interesting that AMV mammary glands exhibited marked up-regulation of Cdc2a and Stmn1, whereas expression of these genes remained unchanged in parous mammary glands after MNU treatment (Fig. 4b). Stmn 1 product (Stathmin) is an important molecule that plays a key role in cell cycle progression. In Jurkat and HeLa cells, the phosphorylation level of Stathmin peaks during the mitotic phase (36). It is interesting that Stathmin is phosphorylated by $\mathrm{Cdc} 2$, a major protein kinase that regulates entry into mitosis $(36,37)$. The marked up-regulation of Stmn 1 and Cdc2a we observed in AMV mammary glands after MNU treatment may be related to subsequent mammary tumor development.

PCNA immunohistochemistry revealed that the mammary epithelial cell proliferation rate was significantly higher in AMV mammary glands than in parous mammary glands after MNU treatment (Fig. 5). This increased proliferation rate of mammary epithelial cells may account for the up-regulation of growth-related genes in AMV mammary glands after MNU treatment. In contrast, after MNU treatment, the PCNA labeling index of parous mammary epithelial cells remained low, and the expression of growth-related genes remained unchanged or was suppressed. These results suggest that MNU acts on alveolar and ductal cells in AMV mammary glands, increasing their rate of proliferation. Consistent with the present findings, previous studies have shown that mammary epithelial cells of virgin mammary glands exhibit a higher proliferation rate after carcinogen challenge than mammary epithelial cells of parous or hormone-treated mammary glands (11). p53 is considered to be a potent mediator of parity- and/or hormone-induced protection against mammary carcinogenesis (38). However, no changes in p53 gene expression were observed in the present study.

After carcinogen challenge, parous mammary glands showed greater refractoriness to epithelial cell proliferation, and exhibited suppression of multiple growth-related genes, whereas AMV mammary glands exhibited greater cell proliferation and up-regulation of growth-related genes. It has previously been hypothesized that the hormonal milieu during pregnancy causes persistent changes in gene expression patterns in the mammary gland via epigenetic modifications in a specific population of cells $(11,15)$. Alterations in gene expression patterns in parous mammary glands after MNU treatment appear to be epigenetic changes induced by parity. In the present study, we identified several genes that may be involved in parity-induced protection against breast cancer. Further investigation of the function and transcriptional regulation of these genes is needed to gain a better understanding of the parity-induced protection mechanisms.

\section{Acknowledgements}

We wish to thank Ms. T. Akamatsu for her technical assistance, and Ms. Y. Yoshida for her help in preparing the manuscript. This work was supported in part by a Grant-inAid for Young Scientists (B) (16790766) and a Grant-in-Aid for Scientific Research (C) (16510047) from the Japan Society for the Promotion of Science. 


\section{References}

1. McPherson K, Steel CM and Dixon JM: ABC of breast diseases. Breast cancer - epidemiology, risk factors, and genetics. BMJ 321: 624-628, 2000.

2. MacMahon B, Cole P, Lin TM, Lowe CR, Mirra AP, Ravnihar B, Salber EJ, Valaoras VG and Yuasa S: Age at first birth and breast cancer risk. Bull World Health Organ 43: 209-221, 1970.

3. Kelsey JL, Gammon MD and John EM: Reproductive factors and breast cancer. Epidemiol Rev 15: 36-47, 1993

4. Thordarson G, Jin E, Guzman RC, Swanson SM, Nandi S and Talamantes F: Refractoriness to mammary tumorigenesis in parous rats: is it caused by persistent changes in the hormonal environment or permanent biochemical alterations in the mammary epithelia? Carcinogenesis 16: 2847-2853, 1995.

5. Yang J, Yoshizawa K, Nandi S and Tsubura A: Protective effects of pregnancy and lactation against $\mathrm{N}$-methyl-N-nitrosoureainduced mammary carcinomas in female Lewis rats. Carcinogenesis 20: 623-628, 1999.

6. Medina D and Smith GH: Chemical carcinogen-induced tumorigenesis in parous, involuted mouse mammary glands. J Natl Cancer Inst 91: 967-969, 1999.

7. Grubbs CJ, Peckham JC and McDonough KD: Effect of ovarian hormones on the induction of 1-methyl-1-nitrosourea-induced mammary cancer. Carcinogenesis 4: 495-497, 1983.

8. Grubbs CJ, Farnell DR, Hill DL and McDonough KC: Chemoprevention of N-nitroso-N-methylurea-induced mammary cancers by pretreatment with 17 beta-estradiol and progesterone. J Natl Cancer Inst 74: 927-931, 1985.

9. Russo IH, Koszalka M and Russo J: Human chorionic gonadotropin and rat mammary cancer prevention. J Natl Cancer Inst 82: 1286-1289, 1990.

10. Srivastava P, Russo J and Russo IH: Chorionic gonadotropin inhibits rat mammary carcinogenesis through activation of programmed cell death. Carcinogenesis 18: 1799-1808, 1997

11. Sivaraman L, Stephens LC, Markaverich BM, Clark JA, Krnacik S, Conneely OM, O'Malley BW and Medina D: Hormone-induced refractoriness to mammary carcinogenesis in Wistar-Furth rats. Carcinogenesis 19: 1573-1581, 1998.

12. Russo J and Russo IH: DNA labeling index and structure of the rat mammary gland as determinants of its susceptibility to carcinogenesis. J Natl Cancer Inst 61: 1451-1459, 1978.

13. Russo J and Russo IH: Biological and molecular bases of mammary carcinogenesis. Lab Invest 57: 112-137, 1987.

14. Russo IH and Russo J: Role of hormones in mammary cancer initiation and progression. J Mammary Gland Biol Neoplasia 3: 49-61, 1998.

15. Ginger MR, Gonzalez-Rimbau MF, Gay JP and Rosen JM: Persistent changes in gene expression induced by estrogen and progesterone in the rat mammary gland. Mol Endocrinol 15: 1993-2009, 2001.

16. D'Cruz CM, Moody SE, Master SR, Hartman JL, Keiper EA, Imielinski MB, Cox JD, Wang JY, Ha SI, Keister BA and Chodosh LA: Persistent parity-induced changes in growth factors, TGF-beta3, and differentiation in the rodent mammary gland. Mol Endocrinol 16: 2034-2051, 2002.

17. Muller YP, Janovjak H, Miserez RA and Dobbie Z: Processing of gene expression data generated by quantitative real-time RTPCR. BioTechniques 32: 75-91, 2002.

18. Stein T, Morris JS, Davies CR, Weber-Hall SJ, Duffy MA, Heath VJ, Bell AK, Ferrier RK, Sandilands GP and Gusterson BA: Involution of the mouse mammary gland is associated with an immune cascade and an acute-phase response, involving LBP, CD14 and STAT3. Breast Cancer Res 6: R75-R91, 2004.

19. Nemir M, Bhattacharyya D, Li X, Singh K, Mukherjee AB and Mukherjee BB: Targeted inhibition of osteopontin expression in the mammary gland causes abnormal morphogenesis and lactation deficiency. J Biol Chem 275: 969-976, 2000.

20. Le Provost F, Cassy S, Hayes H and Martin P: Structure and expression of goat GLYCAM1 gene: lactogenic-dependent expression in ruminant mammary gland and interspecies conservation of the proximal promoter. Gene 313: 83-89, 2003.

21. Prieve MG and Moon RT: Stromelysin-1 and mesothelin are differentially regulated by Wnt-5a and Wnt-1 in C57mg mouse mammary epithelial cells. BMC Dev Biol 3: 2, 2003.
22. Guzman RC, Yang J, Rajkumar L, Thordarson G, Chen X and Nandi S: Hormonal prevention of breast cancer: mimicking the protective effect of pregnancy. Proc Natl Acad Sci USA 96: 2520-2525, 1999.

23. Luetteke NC, Qiu TH, Fenton SE, Troyer KL, Riedel RF, Chang A and Lee DC: Targeted inactivation of the EGF and amphiregulin genes reveals distinct roles for EGF receptor ligands in mouse mammary gland development. Development 126: 2739-2750, 1999.

24. Ma L, Gauville C, Berthois Y, Millot G, Johnson GR and Calvo F: Antisense expression for amphiregulin suppresses tumorigenicity of a transformed human breast epithelial cell line. Oncogene 18: 6513-6520, 1999.

25. LeJeune S, Leek R, Horak E, Plowman G, Greenall M and Harris AL: Amphiregulin, epidermal growth factor receptor, and estrogen receptor expression in human primary breast cancer. Cancer Res 53: 3597-3602, 1993.

26. Okamoto H: The Reg gene family and Reg proteins: with special attention to the regeneration of pancreatic beta-cells. J Hepatobiliary Pancreat Surg 6: 254-262, 1999.

27. Keyomarsi K and Pardee AB: Redundant cyclin overexpression and gene amplification in breast cancer cells. Proc Natl Acad Sci USA 90: 1112-1116, 1993.

28. Yee D, Cullen KJ, Paik S, Perdue JF, Hampton B, Schwartz A, Lippman ME and Rosen N: Insulin-like growth factor II mRNA expression in human breast cancer. Cancer Res 48: 6691-6696, 1988.

29. Figueroa JA, Jackson JG, McGuire WL, Krywicki RF and Yee D: Expression of insulin-like growth factor binding proteins in human breast cancer correlates with estrogen receptor status. J Cell Biochem 52: 196-205, 1993.

30. Bieche I, Lachkar S, Becette V, Cifuentes-Diaz C, Sobel A, Lidereau R and Curmi PA: Overexpression of the stathmin gene in a subset of human breast cancer. Br J Cancer 78: 701-709, 1998.

31. Fantl V, Creer A, Dillon C, Bresnick J, Jackson D, Edwards P, Rosewell I and Dickson C: Fibroblast growth factor signalling and cyclin D1 function are necessary for normal mammary gland development during pregnancy. A transgenic mouse approach. Adv Exp Med Biol 480: 1-7, 2000.

32. Shin HS, Lee HJ, Nishida M, Lee MS, Tamura R, Yamashita S, Matsuzawa Y, Lee IK and Koh GY: Betacellulin and amphiregulin induce upregulation of cyclin D1 and DNA synthesis activity through differential signaling pathways in vascular smooth muscle cells. Circ Res 93: 302-310, 2003

33. D'Amico M, Hulit J, Amanatullah DF, Zafonte BT, Albanese C, Bouzahzah B, Fu M, Augenlicht LH, Donehower LA, Takemaru K, Moon RT, Davis R, Lisanti MP, Shtutman M, Zhurinsky J, Ben-Ze'ev A, Troussard AA, Dedhar S and Pestell RG: The integrin-linked kinase regulates the cyclin D1 gene through glycogen synthase kinase 3 beta and cAMPresponsive element-binding protein-dependent pathways. J Biol Chem 275: 32649-32657, 2000.

34. Hu G, Lee H, Price SM, Shen MM and Abate-Shen C: Msx homeobox genes inhibit differentiation through upregulation of cyclin D1. Development 128: 2373-2384, 2001.

35. Hovey RC, Harris J, Hadsell DL, Lee AV, Ormandy CJ and Vonderhaar BK: Local insulin-like growth factor-II mediates prolactin-induced mammary gland development. Mol Endocrinol 17: 460-471, 2003.

36. Brattsand G, Marklund U, Nylander K, Roos G and Gullberg M: Cell-cycle-regulated phosphorylation of oncoprotein 18 on Ser16, Ser25 and Ser38. Eur J Biochem 220: 359-368, 1994.

37. Luo XN, Mookerjee B, Ferrari A, Mistry S and Atweh GF: Regulation of phosphoprotein p18 in leukemic cells. Cell cycle regulated phosphorylation by p34cdc2 kinase. J Biol Chem 269: 10312-10318, 1994.

38. Sivaraman L, Conneely OM, Medina D and O'Malley BW: p53 is a potential mediator of pregnancy and hormone-induced resistance to mammary carcinogenesis. Proc Natl Acad Sci USA 98: 12379-12384, 2001. 